\title{
A novel device to prevent errors in medication dosing and dispensing
}

\author{
Xing Wu, Guomei Ye, Lili Guo \\ Department of Anesthesiology, Hangzhou Children's Hospital, Hangzhou 310000, China \\ Correspondence to: Xing Wu, MM. Department of Anesthesiology, Hangzhou Children's Hospital, Hangzhou 310000, China. Email: 13705714662@163.com.
}

\begin{abstract}
Erroneous intravenous drug administration has a high probability of causing patient morbidity or mortality during anesthesia. Anesthesiologists are cognizant of this longstanding issue, which has prompted the development of a variety of different protocols and solutions designed to ameliorate the problem and ultimately improve patient outcomes. Unfortunately, no definitive solution has been developed yet. Our invention is a medical device designed to drastically reduce, and hopefully upon further development, refinement and subsequent iterations, completely eradicate the potential for medical errors involving medication misidentification and quantitative errors in anesthetic dosing and dispensing.
\end{abstract}

Keywords: Invention; medication error; anesthesia

Submitted Dec 02, 2019. Accepted for publication Jan 31, 2020.

doi: $10.21037 /$ tp.2020.02.05

View this article at: http://dx.doi.org/10.21037/tp.2020.02.05

\section{Introduction}

Unlike the division of labor between hospital pharmacists and doctors in which doctors write prescriptions which are later dispensed by pharmacists, anesthesiologists do not have the luxury of such compartmentalization and redundancy. An anesthesiologist must be both a dispenser and a user of anesthetic drugs as per the global norm. The process of dosing and dispensing anesthetics is often undertaken by a single anesthesiologist.

Although regulations in many hospital mandate some degree of oversight on the process of drug dosing and dispensing (usually involving a simple double-check by a second individual) in practical application these requirements are either not fulfilled or inadequate to satisfactorily reduce errors. Given the continued high incidence of anesthetic medication errors, understanding the problem and more importantly finding a solution is a major focus of the anesthesiology community $(1,2)$.

However, relying on individual self-discipline to reduce errors in dosing and dispensing drugs has had a limited effect. A more efficient solution is warranted, which will change existing methods and erect normative procedures and automated fail-safe mechanisms. Our invention of a novel medical device is designed to specifically address this unmet need and has been manufactured to specifically prevent medication or equipment misidentification and quantitative errors involving the dosing and dispensing of anesthetics.

\section{Methods}

Using a standard clinical scenario of anesthetic drug dosing and dispensing as our reference point we designed our device as follows. The device consists of two parts. The first part: electronic part (Figure 1). The electronic part consists of a recording portion, broadcast portion and sensor portion. When you press the record button, you can record the content required, such as the name and the dose of the drug. When the drug-loaded syringe is placed on or removed from the electronic device, the device will automatically broadcast the recorded content by triggering the sensor, prompting the manual mechanical check to be performed.

The second part: the drug tray part (Figure 1). The tray is divided into an electronic device portion, a drug label placing portion, and an empty bottle placing portion. The tray is conventionally sized to hold 5 or more syringes in 


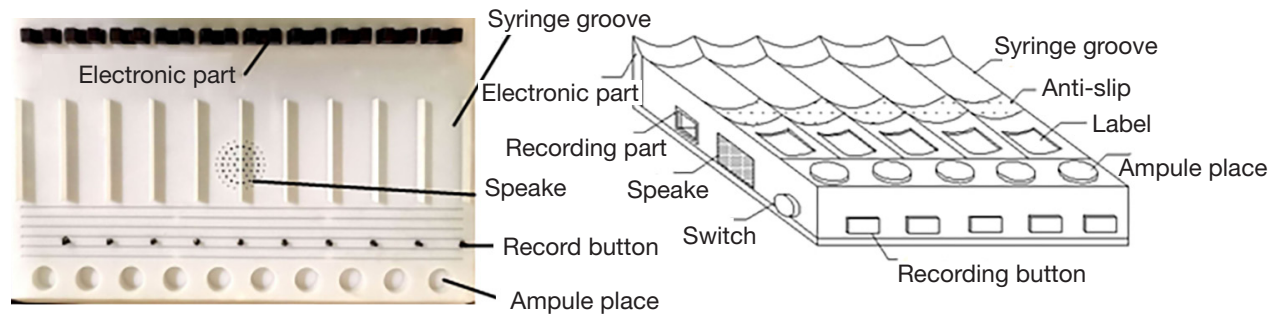

Figure 1 The structure of device.

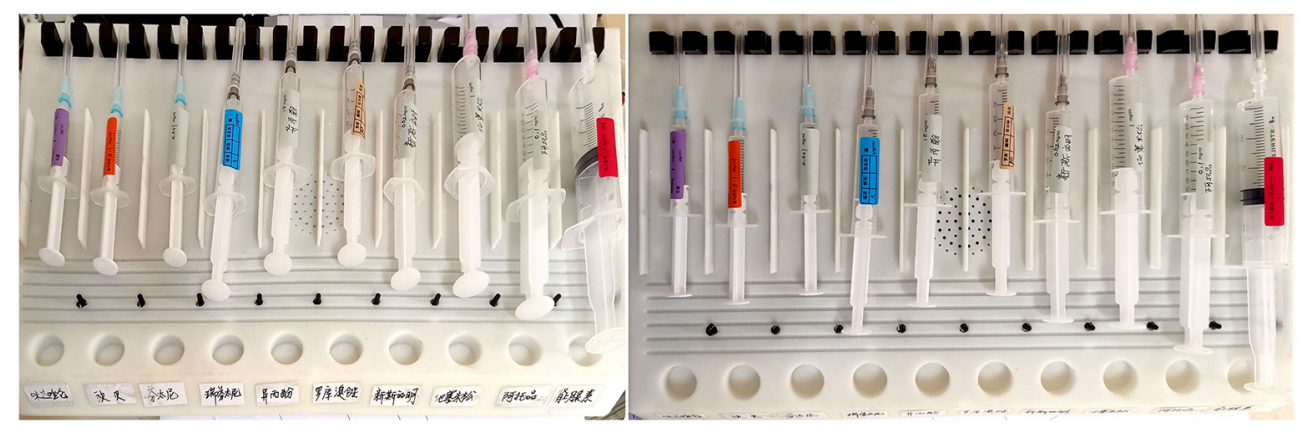

Figure 2 The working prototype of the device.

recessed, molded grooves. According to standard clinical practice, the drug label and the empty bottle are placed facing the anesthesiologist, so that it is possible to easily verify details. The drug-loaded syringe is placed in a groove. The syringe should have a drug label on it, and the tray has been pre-labelled (Figure 2).

We have to initially place the syringes in the tray and pre-record a verbal reminder ("voice tag") describing the contents of each syringe in advance. The department should make a policy that a loaded syringe should in a certain place and won't be changed in the future. Finally, the electronic part automatically broadcasts the pre-recorded content of the syringe allowing the physician to cross-reference this against the empty bottle and the label. In theory, this automated prompt to check should significantly reduce the incidence of medication or equipment misidentification or erroneous anesthetic dosing and dispensing.

Twenty anesthesiologists are selected to test the device. The test is divided into traditional tray group (T Group): syringes with drugs are placed in the tray after labeling; electronic tray group (E group): syringes with drugs are placed in the electronic tray after labeling (Table 1). We initially place the syringes in the tray and pre-record a verbal reminder ("voice tag") describing the contents of each syringe put on the label on the same line. Arrange one person read out the name of the drug, and the tester finds the syringe with the same drug from the tray as soon as possible. Recording the time of taking medicine, whether the testers check the label after taking medicine and whether the tester recommends using the device. Every tester is tested five times and calculate the average time of taking time. SPSS 26 is used for statistical analysis, and t-test is used for comparison between groups, $\mathrm{P}<0.05$ shows the difference is statistically significant.

\section{Results}

Compared with $\mathrm{T}$ group, the $\mathrm{E}$ group takes less time to take medicine and a higher check rate, the difference is statistically significant. All anesthesiologists recommend using the device and they think it is useful to prevent the medication error.

\section{Discussion}

Errors involving dosing and dispensing of anesthetics are a preventable adverse event. The main cause of medication error are dosing errors which account for nearly $50 \%$ of overall incidence. The incidence of medication errors is $0.33-0.73 \%(3-5)$. Errors involving incorrect selection 
Table 1 Comparison table of two groups

\begin{tabular}{lcccc}
\hline Group & $\mathrm{n}$ & Taking time $(\mathrm{s})$ & Rate of checking (\%) & Rate of recommendation (\%) \\
\hline $\mathrm{T}$ & 20 & $5.2 \pm 1.2$ & 85.6 & - \\
$\mathrm{E}$ & 20 & $3.1 \pm 0.8^{\star}$ & $100^{\star}$ & 100 \\
\hline
\end{tabular}

Contrast with T Group, *, $\mathrm{P}<0.05$.

of drugs due to misidentification $(6,7)$, mislabeling and mispackaging (7), incorrect use of over-labels or stickers $(8,9)$, incorrect identification of correct syringe and/ or medication vials (10), mislabeling of syringe, drug dosing calculation errors (11) and other cases have been reported. The ubiquity of these issues and the lack of a practical solution has precipitated a great deal of interest in developing new solutions.

Currently there are a variety of methods used to reduce errors but there is a general trend towards developing and instituting normative standard operating procedures and oversight mechanisms. Jensen et al. (12) developed a series of recommendations to reduce the occurrence of medication errors, including carefully reading the label on the syringe before using the drug, and also suggesting that the drug label should be checked by a second person or checked by an electronic device. Interestingly our device automates the first of Jensen et al.'s recommendations and is a direct realization of the second recommendation.

Our device is most useful in preventing anesthesiologists from taking the wrong syringe. When the syringe is initially loaded, a recorded verbal input detailing the content of the syringe (drug name and dose) is stored in the device. When the syringe is taken off of the device, the name of the drug is automatically broadcasted by the electronic part to remind the drug user to perform a double check, which is then performed manually. The electronic part has a recording function, which allows the dosage of the drug to be recorded and then to be later rebroadcasted to remind the user of the appropriate dosage. We expect this automated redundancy to improve patient outcomes and reduce errors, particularly those made by junior doctors.

Medical errors (and negligence) associated with excessive administration of general anesthetics is a multifaceted problem which requires a multivariate analysis to comprehensively encompass the broad range of contributory factors. Our device offers a solution to several key problems with reference to a standard clinical scenario involving the identification of medication and equipment and subsequent dosing and dispensing. We are still in the process of research and development and expect to further optimize and refine the device to offer an even better solution.

\section{Acknowledgments}

Funding: This study is funded by Hangzhou Science and Technology Bureau and Health Commission of Zhejiang Province.

\section{Footnote}

Conflicts of Interest: The authors have no conflicts of interest to declare.

Ethical Statement: The authors are accountable for all aspects of the work in ensuring that questions related to the accuracy or integrity of any part of the work are appropriately investigated and resolved.

Open Access Statement: This is an Open Access article distributed in accordance with the Creative Commons Attribution-NonCommercial-NoDerivs 4.0 International License (CC BY-NC-ND 4.0), which permits the noncommercial replication and distribution of the article with the strict proviso that no changes or edits are made and the original work is properly cited (including links to both the formal publication through the relevant DOI and the license). See: https://creativecommons.org/licenses/by-nc-nd/4.0/.

\section{References}

1. Wahr JA, Abernathy JH 3rd, Lazarra EH, et al. Medication safety in the operating room: literature and expert-based recommendations. Br J Anaesth 2017;118:32-43.

2. Taylor JA, Loan LA, Kamara J, et al. Medication administration variances before and after implementation of computerized physician order entry in a neonatal intensive care unit. Pediatrics 2008;121:123-8. 
3. Webster CS, Merry AF, Larsson L, et al. The frequency and nature of drug administration error during anaesthesia. Anaesth Intensive Care 2001;29:494-500.

4. Llewellyn RL, Gordon PC, Wheatcroft D, et al. Drug administration errors: a prospective survey from three South African teaching hospitals. Anaesth Intensive Care 2009;37:93-8.

5. Cooper L, DiGiovanni N, Schultz L, et al. Influences observed on incidence and reporting of medication errors in anesthesia. Can J Anesth 2012;59:562-70.

6. Orser B. Reducing medication error. CMAJ 2000;162:1150-1.

7. Skegg PD. Criminal prosecutions of negligent health professionals the New Zealand experience. Med Law Rev 1998;6:220-46.

Cite this article as: $\mathrm{Wu} \mathrm{X}, \mathrm{Ye}$ G, Guo L. A novel device to prevent errors in medication dosing and dispensing. Transl Pediatr 2020;9(2):133-136. doi: 10.21037/tp.2020.02.05
8. Fasting S, Gisvold SE. Adverse drug errors in anaesthesia and the impact of coloured syringe labels. Can J Anesth 2000;47:1060-7.

9. Parry $M$, Morris S. Critical incident involving syringe labels. Anaesthesia 2007;62:95-6.

10. Sakaguchi Y, Tokuda K, Yamaguchi K, et al. Incidence of anesthesia-related medication errors over a 15 -year period in a university hospital. Fukuoka Igaku Zasshi 2008;99:58-66.

11. Orser BA, Chen RJ, Yee DA. Medication errors in anaesthetic practice, a survey of 687 practitioners. Can J Anesth 2001;48:139-46.

12. Jensen LS, Merry AF, Webster CS, et al. Evidence-based strategies for preventing drug administration errors during anaesthesia. Anaesthesia 2004;59:493-504. 